\title{
An Overview of Auditory Training for Cochlear Implant Recipients
}

\author{
Soo Hee Oh \\ Hallym Institute of Advanced International Studies, Seoul, Korea \\ 인공와우 착용자의 청능훈련 \\ 오 수 희 \\ 한림국제대학원대학교 청각언어연구소
}

\begin{abstract}
Auditory training for cochlear implant $(\mathrm{Cl})$ recipients involves complex and interactive processes occurring between sensory and cognitive functions. It does not just facilitate "hearing" but also bridges the gap between "hearing" and "listening comprehension". For this reason, auditory training is applicable to the school-aged or elderly populations, centering on their cognitive abilities. Types of auditory training for $\mathrm{Cl}$ users were determined by learning types, training targets, training methods, training rates, and training materials. Active training involves active auditory learning processes with intensive or extended training programs. Compared to passive auditory learning processes, involving automatic adaptation to electric hearing without training, active training focuses on long term improvements and active user involvements throughout the training session. Due to easy access to training management systems, the computer-assisted auditory training is widely used for active training programs. Although there was substantial individual variability in the magnitude of training benefits, active auditory training using various speech materials for $\mathrm{Cl}$ users provided speech perception benefits in quiet and noise (approximately $10-25 \%$ across test materials). Auditory training using non-speech materials (e.g. indexical information, digits) is related with top-down processes such as memory, attention, or utilization of additional linguistic cues, emphasizing interactive mechanisms between bottom-up and top-down processes. It was reported that trained listeners with non-speech materials achieved improved performance in speech perception tasks, by facilitating the high-level of perceptual processing. Additional factors influencing on training outcomes such as feedbacks or rates were also reviewed.
\end{abstract}

Key Words: Auditory training, Cochlear implant, Speech perception.

Received: March 2, 2016 / Accepted: March 10, 2016

Correspondence: Soo Hee Oh, Hallym Institute of Advanced International Studies, 405 Yeoksam-ro, Gangnam-gu, Seoul 06198, Korea Tel: +82-70-8680-6901 / Fax: +82-2-3453-6618 / E-mail: osh503@naver.com

\section{INTRODUCTION}

청능훈련은 개인의 인지 및 감각기능과 관련된 복합적 상호 과정을 모두 포함하는 것으로, 직접 훈련 받은 내용 이외의 다른 영역에까지 긍정적인 효과를 미친다(Moore \& Amitay, 2007). 이는 단순히 청각 기능을 통한 듣기 능력만을 향상시키는 것이 아니라 훈련 받은 개인의 청각 기능과 이를 통해 듣고 이해하 는 과정을 연결하는 가교 역할을 하기 때문이다. 이러한 이유 로, 청능훈련은 청각 장애가 없는 학령기 아동이나 노인의 인 지 능력을 향상 시키는 훈련도구로도 사용된다.

일반적으로 인공와우 착용자는 음향신호의 전달, 전기신호 의 수신, 그리고 전기자극을 통한 지각이라는 세 단계의 소리
지각 과정을 거친다(Fu \& Galvin, 2011). 이러한 인공와우 착 용자를 대상으로 시행하는 청능훈련은 학습방식의 차이, 청능 훈련의 난이도, 훈련 시 사용되는 자극의 종류, 청능훈련 방법, 그리고 청능훈련 기간 및 빈도(Moore \& Amitay, 2007; Fu \& Galvin, 2011)등의 요소에 따라 훈련 내용과 방법이 결정된다. 본 고찰에서는 청능훈련과 관련된 여러 요인들을 근거로 성인 인공와우 착용자의 다양한 청능훈련을 소개하자 한다. 한편 인 공와우 착용자를 대상으로 음색, 멜로디, 및 음의 고저 등을 중 심으로 시행되는 음악훈련과 연계된 청능훈련(Gfeller et al., 2015)은 본 고찰에서 포함하지 않았다. 


\section{REVIEW}

\section{수동적 학습과 능동적 학습}

수동적 학습은 별도의 청능훈련 없이 인공와우의 전기자극 에 자연스럽게 노출되고 적응되는 과정과 이를 통한 학습을 의 미한다. 수동적 학습은 주로 개개인의 학습방법 차이, 인공와 우 초기 사용 경험, 그리고 개인의 동기등과 밀접한 관계가 있 다. 특히 난청 이전에 언어 발달이 이루어진 성인의 경우, 인공 와우 착용 후 초기 3 6개월 기간 동안 이러한 수동적 학습에 의한 효과가 많이 나타나는 것으로 보고 되었다(Fu \& Galvin, 2011). 한편 인공와우의 전극간 주파수와 와우의 음위상 배열 의(Tonotopic array) 차이는 이러한 수동적 학습 효과에 영향 을 미칠 수 있는 것으로 알려졌는데, 예를 들어 인공와우 내부 전극과 와우간 주파수 스펙트럴(spectral) 불일치 정도가 크지 않을수록 수동적 적응에 좀더 효과적일 수 있다. 인공와우 이 식자의 수동적 학습과 적응을 촉진시키기 위해서는 인공와우 착용으로 인한 초기 스트레스를 줄이고 인공와우 착용자가 점 진적으로 전기자극에 노출될 수 있도록 배려하는 것이 필요하 다(Fu \& Galvin, 2011). 흥미롭게도 수동적 학습 효과는 수동 적으로 소리자극에 노출된 상황에서도 향상될 수 있는 것으로 보고된바 있다(Moore \& Amitay, 2007). 예를 들어 개인이 들 려오는 소리에 집중하지 않고 이를 무시한 상태에서 일정시간 게임에 열중한 뒤에도, 주파수 변별력 검사에서의 향상이 보고 되었고, 이러한 수동적 청각신호 노출 상황에서의 학습 효과는 개인의 집중력과 각성을 포함하는 인지과정과 밀접한 관계가 있는 것으로 설명된다.

능동적 학습은 집중적이고 자발적인 청능훈련 과정과 그에 따른 훈련 효과를 포함한다. 능동적 청능훈련은 개인의 필요와 훈련 목적에 따라 다양한 훈련 과제, 훈련 빈도 및 기간, 그리 고 훈련 방법을 달리하는데, 주로 조용한 곳과 소음 하에서의 말지각 훈련 그리고 음악훈련 등이 포함된다(Fu \& Galvin, 2011). 비록 인공와우 착용자가 수동적 학습을 통해서 말지각 이 향상될 수 있다고 하더라도, 능동적 훈련은 인공와우 착용 자의 자발적 훈련 참여를 촉진시키고 이를 기반으로 좀더 지속 적이고 향상된 훈련효과를 기대해 볼 수 있기 때문에 능동적 청능훈련을 기반으로 시행하는 다양한 청능훈련은 인공와우 착용자에게 반드시 필요하다. 특히 훈련과정에 대한 개입과 추 적이 가능하고 직접 훈련효과를 파악하기 용이한 컴퓨터 기반 의 청능훈련법은 이러한 능동적 학습을 위한 청능훈련 도구로 많이 사용된다(Moore \& Amitay, 2007; Zhang et al., 2014).

\section{조용한 곳과 소음배경하에서의 청능훈련}

조용한 곳 또는 소음배경하에서 시행되는 청능훈련은 말소
리 자극을 사용하여 소음이나 조용한 상황에서 일정기간 동안 정해진 횟수만큼 말지각 훈련을 시행한다. 조용한 곳에서의 말 지각 훈련은 상향식 방법(bottom-up)을 근거로 전반적인 말지 각 향상에 중점을 두는 것에 비해, 소음 배경에서의 말지각 훈 련은 소음하에서의 다양한 상황에 대처할 수 있는 전략을 익 히고 이를 향상 시키는데 중점을 둔다(Fu \& Galvin, 2011).

Fu et al.(2004)은 피검자가 일음절 단어를 사용하여 자기주 도하의 컴퓨터 기반 청능훈련을 매일 한 시간씩 시행하도록 한 뒤 2주마다 음소, 성별구별, 및 소음 배경에서의 문장 검사를 시행하였는데, 그 결과 성별구별 검사를 제외한 나머지 검사에 서 청능훈련 후 15 24\%의 향상을 보였다. 비록 훈련효과의 개 인차는 있었으나, 이는 인공와우 착용자가 매일 한 시간씩 컴퓨 터 기반의 훈련을 통해서 말지각이 향상될 수 있음을 보여주었 고 자기주도하의 컴퓨터 기반 청능훈련 효과의 긍정적 가능성을 제시하였다. 또한 청능훈련 효과는 훈련종료 후 최소 약 4주간 지속 되었으며, 이러한 청능훈련은 기존 인공와우 사용자들이나 인공와우 착용 후 결과가 좋지 않은 착용자들에게도 적용 가능 할 것으로 보고되었다(Fu \& Galvin, 2011). 청능훈련 효과를 적 절하게 측정하기 위해서는 훈련 전 개인의 정확한 베이스라인 (baseline)을 파악하고 측정해야 하며, 훈련목적에 부합되는 적 절한 훈련시간을 배분하고, 개인마다 다른 인공와우 적응기간을 고려하는 등 적절한 훈련효과 측정을 위한 노력과 다양한 훈련 도구에 대한 이해가 동반 되어야 한다(Stacey et al., 2010).

한편 양귀 인공와우 착용자나 보청기와 인공와우를 동시에 착용한 바이모달(bimodal) 상태의 청능훈련에서도 그 훈련효 과가 보고되었다. 한 예로 Zhang et al.(2012)은 하루 한 시간씩 4 주 동안 소음 하에서 자음과 모음을 사용한 청능훈련을 바이 모달 상태에서 시행하였다. 그 결과 자음, 모음, 및 단어 검사에 서 평균 약 $10 \%$ 의 향상을 보였으며 훈련효과는 청능훈련을 끝 낸 뒤 1 개월까지 지속됐다. 그러나 이러한 향상은 바이모달 상 황에서의 저주파수 잔존청력에서 기인된 것이 아니라 인공와 우 착용과 관련된 훈련효과로 설명됐으며, 바이모달 착용자의 잔존청력을 활용한 훈련효과를 명확하게 뒷받침하지 않았다.

\section{말 이외의 자극을 사용한 청능훈련}

말 이외의 훈련 도구를 사용한 청능훈련은 화자인식, 비 어 휘적 요소로 구성된 모음, 숫자 등 말을 제외한 자극을 사용하 여 훈련 참여자의 훈련효과를 측정하고, 훈련이 지각능력 및 학습효과에 미치는 영향을 파악하는데 중점을 둔다. 일반적으 로 이러한 청능훈련은 인공와우 및 바이모달 착용자 또는 가상 적으로 인공와우 상태를 재현한 정상인을 대상으로 시행하였 다. Loebach et al.(2008)은 말 이외의 언어적 정보, 예를 들어 화자의 음성특색을 결정짓는 말투와 화자의 성별, 나이, 또는 
사투리 등을 결정짓는 인덱시컬(indexical) 정보를 사용하여 훈 련한 뒤 그 훈련효과를 측정하고 다양한 경로로 습득되는 지 각능력 학습에 대한 연구를 시행하였다. 훈련결과 문장기술, 화 자 및 성별인지에서 약 10 20\%의 향상을 보였는데 이를 근거 로, 청각자극이 제한된 상황에서의 음향 정보와 인덱시컬 정보 는 서로 상호 작용하며 청자는 이 두 정보를 동일한 지각능력 과정의 선상에서 주어진 정보를 통합하여 해석하고 이해할 수 있음을 설명하였다.

또한 조용한 곳과 소음 배경하에서 화자인지 훈련을 시행한 또 다른 실험에서는(Krull et al., 2012) 바이모달이 일측인공와 우의 경우보다 화자인지 검사에서 약 $7 \%$ 더 향상된 결과를 보 였을 뿐 아니라, 직접 훈련을 시행하지 않았던 문장검사에서도 일측 인공와우와 바이모달 상태에서 향상된 결과를 보였다. 화 자인지 훈련과 관련하여, Levi et al.(2011)은 화자인지 훈련은 단순히 화자의 음향적 특성에 노출되는 훈련이 아니라 청자가 언어의 문맥정보를 통합하는 감각기능과 지각 및 인지기능의 상호 작용 측면에서 이해되어야 함을 강조하였다. 이때 말초기 관에서 받아들여지는 정보의 결여나 손상 정도는 인지 및 지각 과정에도 부정적 영향을 미칠 수 있다(Li \& Fu, 2007).

또 다른 예로 Oba et al.(2011)은 배블(babble) 소음 하에서 숫자를 사용한 훈련을 시행한 뒤, 훈련하지 않았던 문장검사에 서 향상된 결과를 보였음을 보고하였으며, 이는 단순한 숫자를 사용한 청능훈련이 좀더 상위의 인지과정을 촉진한다는 주장 을 뒷받침 하였다. 바꾸어 말하면 말소리 이외의 자극을 사용 한 청능훈련을 통해서 상위 인지기능 예를 들어 기억력, 주의 력, 언어정보 사용과 통합 능력이 향상 될 수 있다는 것이다.

\section{청능훈련 시 피드백의 효과}

청능훈련 시 제시되는 피드백(feedback)은 인공와우 착용자 의 청능훈련 결과에 영향을 미칠 수 있으며, 말소리 스펙트럴 정 보의 결여 정도가 심할수록 더욱 그러하다. Loebach et al. (2010)은 스펙트럴 정보가 제한된 문장 훈련에서 문자로 제공 되는 피드백 효과를 조사한 결과, 문자로 제공되는 피드백은 청자의 지각능력을 촉진시킬 수 있음을 언급하였다. 또한 Kawase et al.(2009)도 청-시각 훈련에서 피드백을 제공하는 것은 훈련 효과를 약 40\%까지 향상 시킬 수 있음을 보고하였고, 훈 련 시 다양한 자극 단서와 시각적 피드백을 제공하는 것은 스 펙트럴 정보가 제한된 상황에서 추가적 단서를 이용하는 훈련 을 통해 청각적 적응력을 향상시킬 수 있는 것으로 설명하였다.

\section{청능훈련 빈도}

인공와우 착용자의 청능훈련과 관련하여 얼마나 자주 어느 정도의 기간 동안 훈련이 필요한가에 대한 질문은 아직까지 정
확하게 답변하기 어려운 부분이다. 앞서 설명한 기존 연구에서 는 비교적 짧은 기간 동안의 훈련효과를 보고하였는데, 대략적 으로 주 5 일 동안 하루 한 시간씩 총 1 개월 기간 동안 청능훈련 을 시행한 것으로 보고하였다. Nogaki et al.(2007)은 스펙트럴 정보가 결여된 상태에서 가상상태의 인공와우 피검자를 대상 으로 훈련기간에 따른 훈련효과 차이를 연구한바 있다. 총 세 그룹 중, 한 그룹은 일주에 한번, 두 번째 그룹은 일주에 두 번, 마지막 세 번째 그룹은 일주에 5번 청능훈련을 시행하였고 자 음, 모음, 문장 검사에서 그 훈련효과를 측정 하였다. 비록 주 5 회 훈련에서 훈련효과가 좀더 향상되는 경향을 보였으나 흥미 롭게도 주 1 회 훈련에서도 훈련효과가 나타났다. 또한 모음 검 사를 제외한 다른 두 검사에서는 세 그룹 모두 훈련 효과에서 의미 있는 차이가 없는 것으로 보고되었다.

\section{SUMMARY}

인공와우 착용자를 대상으로 다양한 말 검사 도구를 사용하 여 조용한 곳이나 소음 배경하에서 컴퓨터 기반 자기주도적 청 능훈련을 시행한 결과 약 10 25\%정도의 말지각 향상을 보였 다. 이러한 훈련효과는 개인에 따라 차이를 보였으나, 훈련을 끝낸 뒤 최소 한달 정도 지속된 것으로 확인 되었다. 한편 인덱 시컬 정보나 숫자 등 말 이외의 자극을 사용한 훈련에서도 상 위 말지각 영역에 긍정적 효과를 미칠 수 있음이 보고되었으며, 말소리 정보가 제한된 상황에서 훈련 시 제공되는 피드백은 청 각 이외의 추가적 단서를 활용하여 훈련효과를 향상 시키는데 기여할 수 있다.

중심 단어 : 청능훈련·인공와우·언어인지.

\section{REFERENCES}

Fu, Q. J., Galvin, J., Wang, X., \& Nogaki, G. (2004). Effects of auditory training on adult cochlear implant patients: a preliminary report. Cochlear Implants International, 5(supp1), S84-S90.

Fu, Q. J. \& Galvin, J. J. (2011). Auditory training for cochlear implant patients. In F. G. Zeng, A. N. Popper, \& R. R. Fay (Eds.), Auditory prostheses: New horizons (Vol. 39) (pp. 257-278). NY: Springer.

Gfeller, K., Guthe, E., Driscoll, V., \& Brown, C. J. (2015). A preliminary report of music-based training for adult cochlear implant users: rationales and development. Cochlear Implants International, 16(Sup3), S22-S31.

Kawase, T., Sakamoto, S., Hori, Y., Maki, A., Suzuki, Y., \& Kobayashi, T. (2009). Bimodal audio-visual training enhances auditory adaptation process. Neuroreport, 20(14), 1231-1234.

Krull, V., Luo, X., \& Kirk, K. I. (2012). Talker-identification training using simulations of binaurally combined electric and acoustic hearing: generalization to speech and emotion recognition. Journal of the Acoustical Society of America, 131(4), 3069-3078.

Li, T. \& Fu, Q. J. (2007). Perceptual adaptation to spectrally shifted vowels: training with nonlexical labels. Journal of the Association for Research in Otolaryngolo, 8(1), 32-41.

Levi, S. V., Winters, S. J., \& Pisoni, D. B. (2011). Effects of cross-language 
voice training on speech perception: Whose familiar voices are more intelligible?. Journal of the Acoustical Society of America, 130(6), 40534062 .

Loebach, J. L., Bent, T., \& Pisoni, D. B. (2008). Multiple routes to the perceptual learning of speech. Journal of the Acoustical Society of America, 124(1), 552-561.

Loebach, J. L., Pisoni, D. B., \& Svirsky, M. A. (2010). Effects of semantic context and feedback on perceptual learning of speech processed through an acoustic simulation of a cochlear implant. Journal of Experimental Psychology: Human Perception and Performance, 36(1), 224234.

Moore, D. R. \& Amitay, S. (2007). Auditory training: rules and applications. Seminars in Hearing, 28(2), 99-109.

Nogaki, G., Fu, Q. J., \& Galvin, J. J. (2007). Effect of training rate on recognition of spectrally shifted speech. Ear and Hearing, 28(2), 132-140.
Oba, S. I., Fu, Q. J., \& Galvin, J. J. (2011). Digit training in noise can improve cochlear implant users' speech understanding in noise. Ear and Hearing, 32(5), 573-581.

Stacey, P. C., Raine, C. H., O’Donoghue, G. M., Tapper, .L, Twomey, T., \& Summerfield, A. Q. (2010). Effectiveness of computer-based auditory training for adult users of cochlear implants. International Journal of Audiology, 49(5), 347-356.

Zhang, T., Dorman, M. F., Fu, Q. J., \& Spahr, A. J. (2012). Auditory training in patients with unilateral cochlear implant and contralateral acoustic stimulation. Ear and Hearing, 33(6), e70-e79.

Zhang, T., Miller, A, \& Campbell, M. M. (2014). Overview of nine compupterized, home-based auditory-training programs for adult cochlear implant recipients. Journal of American Academy Audiology, 25(4), 405-413. 